\title{
A Model for Assessing the Service Quality of University Library Websites
}

\author{
Chung-Min Wu, ${ }^{1}$ Ching-Lin Hsieh, ${ }^{2}$ and Kuei-Lun Chang ${ }^{3}$ \\ ${ }^{1}$ Graduate Institute of Services and Technology Management, National Taipei University of Technology, \\ 1 Zhong Xiao East Road, Section 3, Taipei 106, Taiwan \\ ${ }^{2}$ Graduate Institute of Industrial and Business Management, National Taipei University of Technology, \\ 1 Zhong Xiao East Road, Section 3, Taipei 106, Taiwan \\ ${ }^{3}$ Department of Communications Management, Ming Chuan University, 250 Zhong Shan North Road, Section 5, Taipei 111, Taiwan
}

Correspondence should be addressed to Kuei-Lun Chang; cs821@yahoo.com.tw

Received 22 March 2013; Accepted 12 May 2013

Academic Editor: Tsan-Ming Choi

Copyright (C) 2013 Chung-Min Wu et al. This is an open access article distributed under the Creative Commons Attribution License, which permits unrestricted use, distribution, and reproduction in any medium, provided the original work is properly cited.

Evaluating the e-service quality is essential to organizations. The future of e-libraries has a vital place in universities. Libraries need to use websites as means to provide access to information resources, news and events. The importance of assessing e-service quality of libraries is significant. Previous researchers have developed many methods for assessing e-service quality. However, most of them only focus on the independent hierarchical structure. In this paper, we would like to figure out the criteria for assessing the service quality of library websites from university students' viewpoints. According to interdependent criteria, the analytic network process (ANP) approach is employed to (i) generate the priority weights of each criterion; (ii) measure the service quality of university library websites. 12 web-based service criteria are identified according to 3144 university students' viewpoints based on fuzzy Delphi method. On the basis of past studies, we divide 12 criteria into 3 perspectives, namely, system, efficiency, and information quality to measure the service quality of university library websites. On the basis of 3 perspectives and 12 important criteria, service quality of university library websites could be measured more effectively. Moreover, the practical application to measure the service quality of the old and new versions of one university library website presented in Section 5 is generic and also suitable to be exploited for Taiwanese universities.

\section{Introduction}

The Internet has contributed a convenient and efficient channel for distributing information and services [1]. E-service is becoming increasingly important when determining quality of service delivery in organizations. Evaluating the e-service quality is essential to organizations [2]. Researchers start to investigate the e-service quality of different industries. Libraries are increasingly delivering collections and services electronically [3]. Yalman and Kutluca [4] point out that the Internet is one of the basic tools to provide library services. It is necessary for universities to adopt the concept of e-library and to consider electronic librarianship while restructuring their services they provided. The future of e-libraries has a vital place in universities. Besides providing information about library collection and facilities, libraries need to use websites as means to provide access to information resources, news, and events [5]. The importance of assessing e-service quality of libraries is significant. In this paper, we have identified the criteria to assess the service quality of library websites from university students' viewpoints based on fuzzy Delphi method. Additionally, the ANP approach is employed to generate the priority weights of each criterion and to measure the service quality of university library websites.

Library websites should provide students with real concern contents, information of interest as the premise of the user's demand. Libraries must move away from the view of the click rate transfer to pay attention to the needs of users [6]. As the result, 12 web-based service criteria are identified according to 3144 university students' viewpoints based on fuzzy Delphi method, including choices for searching for information according to users' preference, protection of users' 
personal information, availability of the website, promptness of taking care of problems, simple procedure of application, relevant content can be displayed for each item, downloading speed, promptness of search system response, accurateness of provided information, whether the website updates timely, whether the latest information is provided on the front page, and variety of electronic resources. On the basis of $\mathrm{Hu}[1]$, Parasuraman et al. [7], and Lee and Kozar [8], 12 criteria are taken into 3 perspectives to structure the hierarchy. Unlike previous researchers [8-11] who ignored the interdependence among criteria, this paper utilizes the ANP approach to capture the interdependence of the criteria as it appears to be one of the more feasible and accurate solutions for us to generate the priority weights of each criteria and to measure the service quality of university library websites. The result can provide a foundation for better understanding students' perceptions of e-service quality for libraries. This information is useful to universities libraries website designers and service providers and in the management of web-based services.

\section{Service Quality of Website}

For the purpose of this paper, the evaluating criteria are obtained by reviewing previous literatures as well as collecting students' opinions. The literatures, related to the evaluation of service quality, are described in the following. $\mathrm{Hu}$ [1] points out that traditional Likert scales cannot handle uncertain assessments according to human intuition for the service quality measurement, and so the fuzzy numbers is added and utilized to measure decision makers' subjective preferences. In the paper, $\mathrm{Hu}$ develops a genetic-algorithm-based approach to determine the importance of criteria for assessing the service quality of travel websites. Lin [10] reviews past studies to get 16 criteria for measuring the course website quality. Fuzzy analytic hierarchy process (AHP) is also applied to identify the relative weights of criteria between high and low online learning experience groups. Hu and Liao [11] employ fuzzy multiple criteria decision making approach to obtain important criteria for measuring service quality of Internet banking. Yu et al. [12] use AHP and fuzzy technique for order preference by similarity to ideal solution (TOPSIS) to rank business to consumer (B2C) e-commerce websites in e-alliance. Hsu et al. [13] proposed a process of algorithm that combined the consistent fuzzy preference relations method with ANP to evaluate e-service quality.

A set of initial criteria for measuring the service quality of university library websites are compiled from the abovementioned literatures. As the ANP approach needs more calculations and additional pairwise comparisons, the computing process would be complex if there are too many criteria $[14,15]$. Moreover, some of the initial criteria are unrelated to evaluating library websites. The advantage of fuzzy Delphi method is its simplicity. All the expert opinions can be encompassed in one investigation. Hence, this method can create more effective criteria selection [16]. This paper adopts fuzzy Delphi method to identify the criteria for assessing the service quality of library websites.

\section{Fuzzy Delphi Method}

The Delphi method is a traditional forecasting approach that does not require large samples. It can be utilized to generate a professional consensus for complex topics [17]. The Delphi method suffers from low convergence expert opinions and more execution cost. Murry et al. [18] integrate Delphi method and fuzzy theory. Membership degree is applied to establish the membership function of each participant. Ishikawa et al. [19] also introduce fuzzy theory into Delphi method. Max-min and fuzzy integration algorithm is developed. Hus and Yang [20] apply a triangular fuzzy number to encompass expert opinions and establish a fuzzy Delphi method. The max and min values of expert opinions are taken as the 2 terminal points of triangular fuzzy numbers, and the geometric mean is taken as the membership degree of triangular fuzzy numbers to derive the statistical unbiased effect and avoid the impact of extreme values. Kuo and Chen [21] point out that the advantage of fuzzy Delphi method for collecting group decision is that every expert opinion can be considered and integrated to achieve the consensus of group decisions. Moreover, it reduces the time of investigation and the consumption of cost and time. Ma et al. [16] describe the advantage of fuzzy Delphi method is its simplicity. All the expert opinions can be encompassed in one investigation. Hence, this method can create more effective criteria selection. This paper applies fuzzy Delphi method to identify the criteria for assessing the service quality of library websites.

\section{Method: Analytic Network Process}

In recent years, various researchers have applied the ANP approach in many managerial areas. Liao and Chang [22] apply the ANP approach to select televised sportscasters for Olympic Games. Liao and Chang [23] combine the ANP approach and balanced scorecard (BSC) to select key capabilities of Taiwanese TV-shopping companies. Liao and Chang [24] apply the ANP approach to choose public relations personnel for Taiwanese hospitals. Lin [25] combines ANP with fuzzy preference programming (FPP) to select supplier and then allocates orders among the selected suppliers by multiobjective linear programming (MOLP). Oh et al. [26] apply ANP, and BSC to evaluate the feasibility of a new telecom service. They point out that ANP can get more realistic results. Wu et al. [27] combine ANP with conjoint analysis (CA) to simplify ANP for hospital policymakers making appropriate management policies. Wu et al. [28] apply ANP to select strategic alliance partners for the LCD industry. J. K. Chen and I. S. Chen [29] apply decision-making trial and evaluation laboratory (DEMATEL), fuzzy ANP and TOPSIS to develop a new innovation support system. Liao and Chang [30] combine ANP with BSC for measuring the managerial performance of TV companies. Liao et al. [31] select program suppliers for TV companies using ANP. Lin and Tsai [32] integrate ANP and TOPSIS to select locations for foreign direct investments in new hospitals in China. Tsai and Hsu [33] combine DEMATEL with ANP to select cost of quality models. Tseng [34] uses ANP, DEMATEL, and fuzzy set theory to 
obtain the relative weight of BSC factors for a university performance measurement. Yüksel and Dağdeviren [35] integrate fuzzy ANP and BSC to measure the performance of a manufacturing firm in Turkey. Liao et al. [36] use ANP and TOPSIS for assessing the performance of Taiwanese tour guides. Altuntas et al. [37] apply AHP and ANP to measure hospital service quality. Hu et al. [38] use ANP to evaluate the performance of Taiwan homestay industry. Hsu et al. [13] propose a process of algorithm that combined the consistent fuzzy preference relations method with ANP to evaluate eservice quality. They also point out that ANP is capable of addressing interdependent relationships among criteria. Kang et al. [39] apply fuzzy ANP and interpretive structural modeling (ISM) to select technologies for new product development (NPD).

From the previous literatures, we know that the ANP approach is widely applied in decision making. Compared with the AHP approach, the ANP approach is more accurate and feasible under interdependent situations. This is the reason we choose the ANP approach as our method for generating the priority weights of criteria and measuring the service quality of university library websites. The ANP approach is a comprehensive decision-making technique that captures the outcome of dependency between criteria [40]. The AHP approach serves as a starting point of the ANP approach. Priorities are established in the same way that they are in the AHP approach using pairwise comparisons. The weight assigned to each perspective and criterion may be estimated from the data or subjectively by decision makers. It would be desirable to measure the consistency of the decision makers' judgment. The AHP approach provides a measure through the consistency ratio which is an indicator of the reliability of the model. This ratio is designed in such a way that the values of the ratio exceeding 0.1 indicate inconsistent judgment [41].

\section{Application}

This section can be divided into 2 parts. First, the ANP approach is applied to generate the priority weights of criteria. Second, the ANP approach is employed to measure the service quality of the old and new versions of one university library website.

5.1. Generate the Priority Weights of Criteria. The ANP approach comprises the following steps [40].

Step 1 (model construction and problem structuring). The initial criteria for measuring the service quality of university library websites are compiled from the literatures mentioned in Section 2. Subsequently, the initial criteria are modified according to the opinions of university students using questionnaires developed based on Likert seven-point scale, with 1 as most unimportant and 7 as most important. Questionnaires are sent to 3144 university students to obtain their opinions about the importance of criteria. A demographic and behavioral characteristic profile of the respondents is shown in the appendix. Among the 3144 respondents, 1148 respondents (36.51\%) are males and 1996 respondents are female (63.49\%). About 19\% of the respondents are at the graduate school level or above. Almost one-fourth of the respondents are from the College of Management, followed by the College of Social Sciences, the College of Liberal Arts, the College of Science, and the College of Life Science. 57 respondents (1.81\%) access the library website more than 20 times per month. $7.63 \%$ of respondents use library website above 5 hours per week.

On the basis of fuzzy Delphi method, the geometric mean of each criterion is used to denote the consensus of the respondents' evaluation value of the criteria. According to the geometric mean values, top 12 web-based service criteria are identified, including choices for searching for information according to users' preference, protection of users' personal information, availability of the website, promptness of taking care of problems, simple procedure of application, relevant content can be displayed for each item, downloading speed, promptness of search system response, accurateness of provided information, whether the website updates timely, whether the latest information is provided on the front page, and variety of electronic resources. The contributors of the criteria are shown in Table 1. Based on Hu [1], Parasuraman et al. [7], and Lee and Kozar [8], this study proposes a hierarchy, illustrated in Figure 1, to evaluate the e-service quality of libraries in universities. Unlike previous researchers [811] who ignored the interdependence among criteria, in this paper, the ANP approach, which captures the interdependence, appears to be one of the more feasible and accurate solutions for us to generate the priority weights of each criteria and to measure the service quality of university library websites.

Only 44 students who access the library website more than 20 times per month and also use the library website above 5 hours per week are selected as respondents for the ANP questionnaires. We sent the ANP questionnaires to them by e-mail and personally. 34 ANP questionnaires are collected. Deducting questionnaires those consistency ratios exceeding 0.1, 25 ANP questionnaires are retained to generate the priority weights of criteria.

Step 2 (determine the perspectives and criteria weights). In this step, 25 students make a series of pairwise comparisons to establish the relative importance of perspectives. In these comparisons, a one-nine scale is applied to compare the 2 perspectives. The pairwise comparison matrix and the development of each perspective priority weight are shown in Table 2.

According to the interdependency of criteria, we apply pairwise comparisons again to establish the criteria relationships within each perspective. The eigenvector of the observable pairwise comparison matrix provide the criteria weights at this level, which will be used in the supermatrix. With respect to choices for searching for information according to users' preference, for example, a pairwise comparison within the system perspective can be shown in Table 3. According to this way, we can derive every criterion weight to obtain the supermatrix. 
TABLE 1: Contributors of the criteria.

\begin{tabular}{|c|c|c|c|c|}
\hline \multicolumn{3}{|l|}{ Criteria } & Contributor & \\
\hline \multicolumn{3}{|c|}{$\begin{array}{l}\text { Choices for searching for information } \\
\text { according to users' preference }\end{array}$} & {$[1,13]$} & \\
\hline \multicolumn{3}{|c|}{ Protection of users' personal information } & {$[1,7-9,11,13$} & \\
\hline \multicolumn{3}{|c|}{ Availability of the website } & {$[1,7]$} & \\
\hline \multicolumn{3}{|c|}{ Promptness of taking care of problems } & {$[1,2,7,11]$} & \\
\hline \multicolumn{3}{|c|}{ Simple procedure of application } & {$[1-3,10-13$} & \\
\hline \multicolumn{3}{|c|}{$\begin{array}{l}\text { Relevant content can be displayed for } \\
\text { each item }\end{array}$} & {$[1,3]$} & \\
\hline \multicolumn{3}{|c|}{ Downloading speed } & {$[3,7,13]$} & \\
\hline \multicolumn{3}{|c|}{ Promptness of search system response } & {$[1-3,10]$} & \\
\hline \multicolumn{3}{|c|}{ Accurateness of provided information } & {$[1,2,8-11]$} & \\
\hline \multicolumn{3}{|c|}{ Whether the website updates timely } & {$[10]$} & \\
\hline \multicolumn{3}{|c|}{$\begin{array}{l}\text { Whether the latest information is } \\
\text { provided on the front page }\end{array}$} & Students propc & osed \\
\hline \multicolumn{3}{|c|}{ Variety of electronic resources } & {$[3,8]$} & \\
\hline \multicolumn{5}{|c|}{ Assessing the service quality of university library websites } \\
\hline System & Efficiency & Info & ation quality & \\
\hline \multirow{2}{*}{$\begin{array}{l}C_{1}: \text { choices for } \\
\text { searching for } \\
\text { information } \\
\text { according to users' } \\
\text { preference }\end{array}$} & $\mid \begin{array}{l}C_{4}: \text { promptness of } \\
\text { taking care of } \\
\text { problems }\end{array}$ & $\begin{array}{r}C_{9}: \text { ac } \\
\text { prov }\end{array}$ & $\begin{array}{l}\text { ateness of } \\
\text { d information }\end{array}$ & \\
\hline & \multirow{2}{*}{$\begin{array}{l}C_{5}: \text { simple } \\
\text { procedure of } \\
\text { application }\end{array}$} & $\begin{array}{l}C_{10}: \mathrm{w} \\
\text { updat }\end{array}$ & $\begin{array}{l}\text { her the website } \\
\text { mely }\end{array}$ & 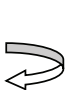 \\
\hline \multirow{2}{*}{$\begin{array}{l}C_{2}: \text { protection of } \\
\text { users' personal } \\
\text { information }\end{array}$} & & \multirow{2}{*}{\multicolumn{2}{|c|}{$\begin{array}{l}C_{11}: \text { whether the latest } \\
\text { information is provided } \\
\text { on the front page }\end{array}$}} & \\
\hline & \multirow{2}{*}{$\begin{array}{l}C_{6}: \text { relevant } \\
\text { content can be } \\
\text { displayed for each } \\
\text { item }\end{array}$} & & & \\
\hline \multirow[t]{3}{*}{$\begin{array}{l}C_{3} \text { : availability of } \\
\text { the website }\end{array}$} & & \multirow{3}{*}{\multicolumn{3}{|c|}{$\begin{array}{l}C_{12}: \text { variety of electronic } \\
\text { resources }\end{array}$}} \\
\hline & $\begin{array}{l}C_{7} \text { : downloading } \\
\text { speed }\end{array}$ & & & \\
\hline & $\begin{array}{l}C_{8}: \text { promptness of } \\
\text { search system } \\
\text { response }\end{array}$ & & & \\
\hline
\end{tabular}

FIGURE 1: Hierarchy for assessing the service quality of university library websites.

Step 3 (construct and solve the supermatrix). An example of supermatrix is show in Figure 2. The components are $C_{k}$, $k=1, \ldots, n$, and each component $k$ has $m_{k}$ elements, denoted by $e_{k 1}, e_{k 2}, \ldots, e_{k m k}$. The eigenvector obtained in Step 2 are grouped and located in appropriate positions in the supermatrix on the basis of the influences. The criteria weights derived from Step 2 are used to get the column of the supermatrix as shown in Table 4. Finally, the system solution is derived by multiplying the supermatrix of model variables by itself, which accounts for variable interaction, until the system's row values converge to the same value for each column of the matrix, as shown in Table 5.

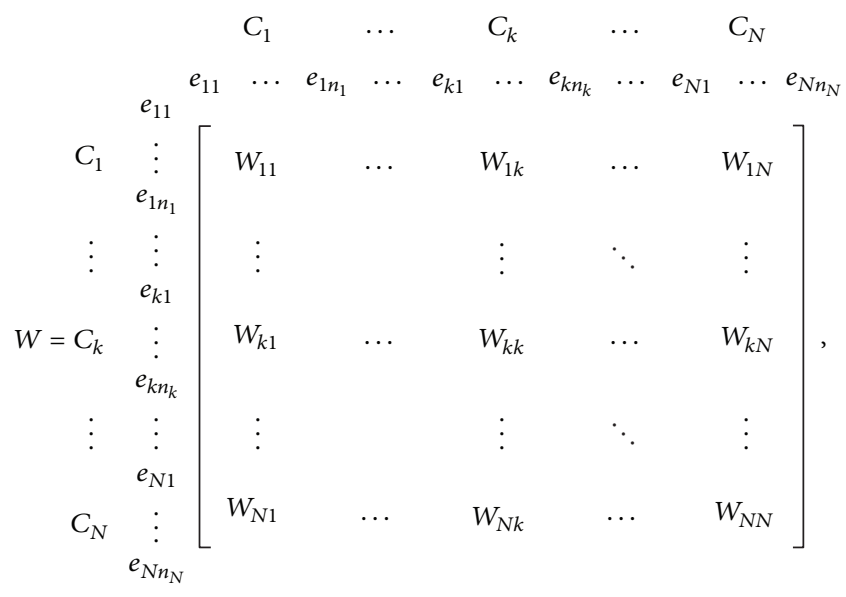

Figure 2: An example of supermatrix.

According to Tables 2 and 5, we can aggregate the total weight of criteria as shown in Table 6. According to Table 6, protection of users' personal information is the most important factor to measure the service quality of library website, followed by choices for searching for information according to users' preference, availability of the website, accurateness of provided information, whether the website updates timely, promptness of taking care of problems, variety of electronic resources, simple procedure of application, whether the latest information is provided on the front page, promptness of search system response, relevant content can be displayed for each item, and downloading speed.

\subsection{Measure the Service Quality of University Library Websites.} In the second part, the ANP approach is applied to measure the service quality of the old and new versions of one university library website.

Step 1 (model construction and problem structuring). According to hierarchy, the service quality of old and new versions of one university library website is evaluated. We sent the ANP questionnaires to 50 graduate school students personally. Deducting the ANP questionnaires that the consistency ratio is exceeding 0.1, 20 ANP questionnaires are retained to assessing the service quality of library websites.

Step 2 (determine the perspectives and criteria weights). In this step, 20 graduate school students make a series of pairwise comparisons to establish the relative importance of perspectives. In these comparisons, a one-nine scale is applied to compare the 2 perspectives. The pairwise comparison matrix and the development of each perspective priority weight are shown in Table 7. According to the interdependency of criteria, we apply pairwise comparisons again to establish the criteria relationships within each perspective. The eigenvector of the observable pairwise comparison matrix provide the criteria weights at this level, which will be used in the supermatrix.

Step 3 (construct and solve the supermatrix). The criteria weights derived from Step 2 are used to get the column of the 
TABLE 2: The pairwise comparisons of perspectives.

\begin{tabular}{lcccc}
\hline & System & Efficiency & \multicolumn{2}{c}{ Information quality } \\
& & & $\lambda_{\max }=3.0010$ C.R. $=0.0007$ & Weights \\
\hline System & 1.0000 & 1.0118 & 1.0481 & 0.3399 \\
Efficiency & 0.9883 & 1.0000 & 0.9456 & 0.3258 \\
Information quality & 0.9541 & 1.0576 & 1.0000 & 0.3343 \\
\hline
\end{tabular}

TABLE 3: The pairwise comparisons within system perspective with respect to choices for searching for information according to users' preference.

\begin{tabular}{|c|c|c|c|}
\hline & Protection of users' personal information & Availability of the website & \multirow{2}{*}{ Weights } \\
\hline & \multicolumn{2}{|c|}{$\lambda_{\max }=2.0000$ C.R. $=0.0000$} & \\
\hline Protection of users' personal information & 1.0000 & 1.0524 & 0.5128 \\
\hline Availability of the website & 0.9502 & 1.0000 & 0.4872 \\
\hline
\end{tabular}

TABLE 4: The supermatrix before convergence.

\begin{tabular}{|c|c|c|c|c|c|c|c|c|c|c|c|c|}
\hline & $C_{1}$ & $C_{2}$ & $C_{3}$ & $\mathrm{C}_{4}$ & $C_{5}$ & $C_{6}$ & $C_{7}$ & $C_{8}$ & $C_{9}$ & $C_{10}$ & $C_{11}$ & $C_{12}$ \\
\hline$\overline{C_{1}}$ & 0.0000 & 0.5046 & 0.4843 & & & & & & & & & \\
\hline$C_{2}$ & 0.5128 & 0.0000 & 0.5157 & & & & & & & & & \\
\hline$C_{3}$ & 0.4872 & 0.4954 & 0.0000 & & & & & & & & & \\
\hline$C_{4}$ & & & & 0.0000 & 0.4018 & 0.3300 & 0.3206 & 0.2975 & & & & \\
\hline$C_{5}$ & & & & 0.3358 & 0.0000 & 0.3008 & 0.2648 & 0.2598 & & & & \\
\hline$C_{6}$ & & & & 0.2482 & 0.1830 & 0.0000 & 0.2121 & 0.2547 & & & & \\
\hline$C_{7}$ & & & & 0.1584 & 0.1763 & 0.1862 & 0.0000 & 0.1880 & & & & \\
\hline$C_{8}$ & & & & 0.2576 & 0.2389 & 0.1830 & 0.2026 & 0.0000 & & & & \\
\hline$C_{9}$ & & & & & & & & & 0.0000 & 0.4345 & 0.3194 & 0.4406 \\
\hline$C_{10}$ & & & & & & & & & 0.3778 & 0.0000 & 0.3963 & 0.2941 \\
\hline$C_{11}$ & & & & & & & & & 0.2949 & 0.2348 & 0.0000 & 0.2653 \\
\hline$C_{12}$ & & & & & & & & & 0.3273 & 0.3307 & 0.2843 & 0.0000 \\
\hline
\end{tabular}

TABLE 5: The supermatrix after convergence.

\begin{tabular}{|c|c|c|c|c|c|c|c|c|c|c|c|c|}
\hline & $C_{1}$ & $C_{2}$ & $C_{3}$ & $C_{4}$ & $C_{5}$ & $C_{6}$ & $C_{7}$ & $C_{8}$ & $C_{9}$ & $C_{10}$ & $C_{11}$ & $C_{12}$ \\
\hline$\overline{C_{1}}$ & 0.3309 & 0.3309 & 0.3309 & & & & & & & & & \\
\hline$C_{2}$ & 0.3396 & 0.3396 & 0.3396 & & & & & & & & & \\
\hline$C_{3}$ & 0.3295 & 0.3295 & 0.3295 & & & & & & & & & \\
\hline$C_{4}$ & & & & 0.2549 & 0.2549 & 0.2549 & 0.2549 & 0.2549 & & & & \\
\hline$C_{5}$ & & & & 0.2282 & 0.2282 & 0.2282 & 0.2282 & 0.2282 & & & & \\
\hline$C_{6}$ & & & & 0.1836 & 0.1836 & 0.1836 & 0.1836 & 0.1836 & & & & \\
\hline$C_{7}$ & & & & 0.1494 & 0.1494 & 0.1494 & 0.1494 & 0.1494 & & & & \\
\hline$C_{8}$ & & & & 0.1840 & 0.1840 & 0.1840 & 0.1840 & 0.1840 & & & & \\
\hline$C_{9}$ & & & & & & & & & 0.2870 & 0.2870 & 0.2870 & 0.2870 \\
\hline$C_{10}$ & & & & & & & & & 0.2624 & 0.2624 & 0.2624 & 0.2624 \\
\hline$C_{11}$ & & & & & & & & & 0.2101 & 0.2101 & 0.2101 & 0.2101 \\
\hline$C_{12}$ & & & & & & & & & 0.2405 & 0.2405 & 0.2405 & 0.2405 \\
\hline
\end{tabular}

supermatrix as shown in Table 8. Finally, the system solution is derived by multiplying the supermatrix of model variables by itself, which accounts for variable interaction, until the system's row values converge to the same value for each column of the matrix, as shown in Table 9.

Step 4 (select the best alternative). The weight of each alternative with respect to the criteria is shown in Table 10. According to Tables 7, 9, and 10, we can aggregate the total weight of each alternative as shown in Table 11. Therefore, it is obvious that the e-service quality of new version is better than old one.

\section{Conclusion}

The importance of assessing e-service quality of libraries is significant. Researchers have developed many methods for 
TABLE 6: The total weight of criteria.

\begin{tabular}{lccc}
\hline & Weight of supermatrix after convergence & Perspective priority weight & Total weight \\
\hline$C_{1}$ & 0.3309 & 0.3399 & 0.1125 \\
$C_{2}$ & 0.3396 & 0.3399 & 0.1154 \\
$C_{3}$ & 0.3295 & 0.3399 & 0.1120 \\
$C_{4}$ & 0.2549 & 0.3258 & 0.0831 \\
$C_{5}$ & 0.2282 & 0.3258 & 0.0743 \\
$C_{6}$ & 0.1836 & 0.3258 & 0.0598 \\
$C_{7}$ & 0.1494 & 0.3258 & 0.0487 \\
$C_{8}$ & 0.1840 & 0.3258 & 0.0600 \\
$C_{9}$ & 0.2870 & 0.3343 & 0.0960 \\
$C_{10}$ & 0.2624 & 0.3343 & 0.0877 \\
$C_{11}$ & 0.2101 & 0.3343 & 0.0702 \\
$C_{12}$ & 0.2405 & 0.3343 & 0.0804 \\
\hline
\end{tabular}

TABLE 7: The pairwise comparisons of perspectives.

\begin{tabular}{lcccc}
\hline & System & Efficiency & Information quality & Weights \\
& & \multicolumn{2}{c}{$\lambda_{\max }=3.0047$ C.R. $=0.0036$} & 1.1914 \\
System & 1.0000 & 1.0845 & 0.8941 & 0.3623 \\
Efficiency & 0.9221 & 1.0000 & 1.0000 & 0.3119 \\
Information quality & 0.8394 & 1.1184 & 0.3257 \\
\hline
\end{tabular}

TABLE 8: The supermatrix before convergence.

\begin{tabular}{|c|c|c|c|c|c|c|c|c|c|c|c|c|}
\hline & $C_{1}$ & $C_{2}$ & $C_{3}$ & $C_{4}$ & $C_{5}$ & $C_{6}$ & $C_{7}$ & $C_{8}$ & $C_{9}$ & $C_{10}$ & $C_{11}$ & $C_{12}$ \\
\hline$C_{1}$ & 0.0000 & 0.4063 & 0.4343 & & & & & & & & & \\
\hline$C_{2}$ & 0.4563 & 0.0000 & 0.5657 & & & & & & & & & \\
\hline$C_{3}$ & 0.5437 & 0.5937 & 0.0000 & & & & & & & & & \\
\hline$C_{4}$ & & & & 0.0000 & 0.4276 & 0.3184 & 0.2582 & 0.2985 & & & & \\
\hline$C_{5}$ & & & & 0.2912 & 0.0000 & 0.3404 & 0.2756 & 0.2563 & & & & \\
\hline$C_{6}$ & & & & 0.2426 & 0.1826 & 0.0000 & 0.2348 & 0.2789 & & & & \\
\hline$C_{7}$ & & & & 0.1377 & 0.1532 & 0.1551 & 0.0000 & 0.1663 & & & & \\
\hline$C_{8}$ & & & & 0.3284 & 0.2366 & 0.1860 & 0.2314 & 0.0000 & & & & \\
\hline$C_{9}$ & & & & & & & & & 0.0000 & 0.5189 & 0.3672 & 0.4794 \\
\hline$C_{10}$ & & & & & & & & & 0.3553 & 0.0000 & 0.4205 & 0.2999 \\
\hline$C_{11}$ & & & & & & & & & 0.2902 & 0.1663 & 0.0000 & 0.2207 \\
\hline$C_{12}$ & & & & & & & & & 0.3546 & 0.3148 & 0.2123 & 0.0000 \\
\hline
\end{tabular}

TABLE 9: The supermatrix after convergence.

\begin{tabular}{|c|c|c|c|c|c|c|c|c|c|c|c|c|}
\hline & $C_{1}$ & $C_{2}$ & $C_{3}$ & $C_{4}$ & $C_{5}$ & $C_{6}$ & $C_{7}$ & $C_{8}$ & $C_{9}$ & $C_{10}$ & $C_{11}$ & $C_{12}$ \\
\hline$C_{1}$ & 0.2961 & 0.2961 & 0.2961 & & & & & & & & & \\
\hline$C_{2}$ & 0.3406 & 0.3406 & 0.3406 & & & & & & & & & \\
\hline$C_{3}$ & 0.3632 & 0.3632 & 0.3632 & & & & & & & & & \\
\hline$C_{4}$ & & & & 0.2511 & 0.2511 & 0.2511 & 0.2511 & 0.2511 & & & & \\
\hline$C_{5}$ & & & & 0.2257 & 0.2257 & 0.2257 & 0.2257 & 0.2257 & & & & \\
\hline$C_{6}$ & & & & 0.1894 & 0.1894 & 0.1894 & 0.1894 & 0.1894 & & & & \\
\hline$C_{7}$ & & & & 0.1321 & 0.1321 & 0.1321 & 0.1321 & 0.1321 & & & & \\
\hline$C_{8}$ & & & & 0.2017 & 0.2017 & 0.2017 & 0.2017 & 0.2017 & & & & \\
\hline$C_{9}$ & & & & & & & & & 0.3168 & 0.3168 & 0.3168 & 0.3168 \\
\hline$C_{10}$ & & & & & & & & & 0.2616 & 0.2616 & 0.2616 & 0.2616 \\
\hline$C_{11}$ & & & & & & & & & 0.1872 & 0.1872 & 0.1872 & 0.1872 \\
\hline$C_{12}$ & & & & & & & & & 0.2344 & 0.2344 & 0.2344 & 0.2344 \\
\hline
\end{tabular}


TABLE 10: The weight of each alternative with respect to criteria.

\begin{tabular}{lcc}
\hline & $\begin{array}{c}\text { New version of library } \\
\text { website }\end{array}$ & $\begin{array}{c}\text { Old version of library } \\
\text { website }\end{array}$ \\
\hline$C_{1}$ & 0.5993 & 0.4007 \\
$C_{2}$ & 0.4453 & 0.5547 \\
$C_{3}$ & 0.5000 & 0.5000 \\
$C_{4}$ & 0.5547 & 0.4453 \\
$C_{5}$ & 0.5689 & 0.4311 \\
$C_{6}$ & 0.5000 & 0.5000 \\
$C_{7}$ & 0.5346 & 0.4654 \\
$C_{8}$ & 0.4453 & 0.5547 \\
$C_{9}$ & 0.5000 & 0.5000 \\
$C_{10}$ & 0.5255 & 0.4745 \\
$C_{11}$ & 0.4453 & 0.5547 \\
$C_{12}$ & 0.6322 & 0.3678 \\
\hline
\end{tabular}

TABLE 11: The total weight of alternatives.

\begin{tabular}{lcccc}
\hline & Weight of supermatrix after convergence & Perspective priority weight & New version of library website & Old version of library website \\
\hline$C_{1}$ & 0.2961 & 0.3623 & 0.0643 & 0.0430 \\
$C_{2}$ & 0.3406 & 0.3623 & 0.0550 & 0.0685 \\
$C_{3}$ & 0.3632 & 0.3623 & 0.0658 & 0.0658 \\
$C_{4}$ & 0.2511 & 0.3119 & 0.0435 & 0.0349 \\
$C_{5}$ & 0.2257 & 0.3119 & 0.0401 & 0.0304 \\
$C_{6}$ & 0.1894 & 0.3119 & 0.0295 & 0.0295 \\
$C_{7}$ & 0.1321 & 0.3119 & 0.0220 & 0.0192 \\
$C_{8}$ & 0.2017 & 0.3119 & 0.0280 & 0.0349 \\
$C_{9}$ & 0.3168 & 0.3257 & 0.0516 & 0.0516 \\
$C_{10}$ & 0.2616 & 0.3257 & 0.0448 & 0.0404 \\
$C_{11}$ & 0.1872 & 0.3257 & 0.0271 & 0.0338 \\
$C_{12}$ & 0.2344 & 0.3257 & 0.0483 & 0.0281 \\
\hline \multicolumn{2}{r}{ Total weight } & 0.5199 & 0.4801 \\
\hline
\end{tabular}

assessing e-service quality. However, most of them only focus on the independent hierarchical structure. In this paper, we figure out the criteria for assessing the service quality of library websites from university students' viewpoints based on fuzzy Delphi method. The ANP approach is employed to generate the priority weights of criteria and to measure the service quality of university library websites. 12 web-based service criteria are identified according to 3144 university students' viewpoints, including choices for searching for information according to users' preference, protection of users' personal information, availability of the website, promptness of taking care of problems, simple procedure of application, relevant content can be displayed for each item, downloading speed, promptness of search system response, accurateness of provided information, whether the website updates timely, whether the latest information is provided on the front page, and variety of electronic resources. According to past studies, 12 criteria are taken into 3 perspectives to structure the hierarchy. Unlike previous researchers who ignored the interdependence among criteria, in this paper, the ANP approach capturing the interdependence appears to be one of the most feasible and accurate solutions for us to generate the priority weights of each criterion and measure the service quality of university library websites.

Finally, we find that protection of users' personal information is the most important factor to measure the service quality of library website, followed by choices for searching for information according to users' preference, availability of the website, accurateness of provided information, whether the website updates timely, promptness of taking care of problems, variety of electronic resources, simple procedure of application, whether the latest information is provided on the front page, promptness of search system response, relevant content can be displayed for each item, and downloading speed. The design of university library websites and services should be in accordance with characteristics of users. This result also helps universities libraries website designers and service providers to put extra emphasis on to maintain or increase students' perception of overall e-service quality. For example, university library websites should spend more effort on the ease of use of their websites for finding information and keeping user information safer. Library website should 
TABLE 12: Demographic and behavioral characteristic profile of respondents $(n=3144)$.

\begin{tabular}{|c|c|c|}
\hline Variable & $N$ & $\%$ \\
\hline \multicolumn{3}{|l|}{ Gender } \\
\hline Male & 1148 & 36.51 \\
\hline Female & 1996 & 63.49 \\
\hline \multicolumn{3}{|l|}{ Age } \\
\hline $18-28$ & 2626 & 83.52 \\
\hline $29-39$ & 471 & 14.98 \\
\hline $40-49$ & 47 & 1.50 \\
\hline \multicolumn{3}{|l|}{ Education } \\
\hline University & 2547 & 81.01 \\
\hline Graduate school & 496 & 15.77 \\
\hline Ph.D. student & 101 & 3.22 \\
\hline \multicolumn{3}{|l|}{ Field of Study } \\
\hline College of Liberal Arts & 378 & 12.02 \\
\hline College of Engineering & 192 & 6.11 \\
\hline College of Medicine & 141 & 4.48 \\
\hline College of Science & 287 & 9.13 \\
\hline $\begin{array}{l}\text { College of Electrical Engineering and Computer } \\
\text { Science }\end{array}$ & 194 & 6.17 \\
\hline College of Social Sciences & 542 & 17.23 \\
\hline College of Management & 753 & 23.95 \\
\hline College of Law & 144 & 4.58 \\
\hline College of Life Science & 247 & 7.86 \\
\hline College of Education & 209 & 6.65 \\
\hline College of Bioresources and Agriculture & 57 & 1.82 \\
\hline \multicolumn{3}{|l|}{ Frequency of library website visit per month } \\
\hline$<5$ & 1941 & 61.74 \\
\hline $5-10$ & 564 & 17.93 \\
\hline $11-15$ & 412 & 13.11 \\
\hline $16-20$ & 170 & 5.41 \\
\hline More than 20 & 57 & 1.81 \\
\hline \multicolumn{3}{|l|}{ Hours of library website usage per week } \\
\hline$<1$ & 1755 & 55.82 \\
\hline $1-3$ & 675 & 21.47 \\
\hline $3.1-5$ & 474 & 15.08 \\
\hline More than 5 & 240 & 7.63 \\
\hline
\end{tabular}

get users the right information in minimal time and effort. Established online instructions can help users to search for the needed information. Provided easy access to a wellorganized collection of information resources is also vital. When user assesses the library website, he or she approaches it by perceiving how easy it is to gain access to the service, in terms of the convenience of using the websites. Moreover, the practical application to measure the service quality of the old and new versions of one university library website presented in Section 5 is generic and also suitable to be exploited for Taiwanese universities.
The hierarchy proposed in this paper considers 12 critical criteria. We suggest that future research studies can incorporate more criteria in order to conduct more accurate estimates. Moreover, follow-up researchers could analyze this topic with the concept of fuzzy sets or combining ANP with other multiple criteria decision making (MCDM) approaches such as DEMATEL and TOPSIS.

\section{Appendix}

See Table 12 .

\section{References}

[1] Y. C. Hu, "Fuzzy multiple-criteria decision making in the determination of critical criteria for assessing service quality of travel websites," Expert Systems with Applications, vol. 36, no. 3, pp. 6439-6445, 2009.

[2] S. M. Amin and U. N. U. Ahmad, "The attributes of electronic service quality (e-SQ) among academic librarians," ProcediaSocial and Behavioral Sciences, vol. 65, pp. 260-265, 2012.

[3] P. Hernon and P. Calvert, "E-service quality in libraries: exploring its features and dimensions," Library and Information Science Research, vol. 27, no. 3, pp. 377-404, 2005.

[4] M. Yalman and T. Kutluca, "Future of e-libraries in universities," Procedia-Social and Behavioral Sciences, vol. 47, pp. 2225-2228, 2012.

[5] T. D. Sarkar, "Impact of online interactivity dimensions on library website quality," Annals of Library and Information Studies, vol. 59, pp. 231-239, 2012.

[6] I. Rowlands, D. Nicholas, P. Williams et al., "The Google generation: the information behaviour of the researcher of the future," Aslib Proceedings: New Information Perspectives, vol. 60, no. 4, pp. 290-310, 2008.

[7] A. Parasuraman, V. A. Zeithaml, and A. Malhotra, "E-S-QUAL a multiple-item scale for assessing electronic service quality," Journal of Service Research, vol. 7, no. 3, pp. 213-233, 2005.

[8] Y. Lee and K. A. Kozar, "Investigating the effect of website quality on e-business success: an analytic hierarchy process (AHP) approach," Decision Support Systems, vol. 42, no. 3, pp. 13831401, 2006.

[9] Y. Sun, S. He, and J. Y. Leu, "Syndicating web services: a QoS and user-driven approach," Decision Support Systems, vol. 43, no. 1, pp. 243-255, 2007.

[10] H. F. Lin, "An application of fuzzy AHP for evaluating course website quality," Computers and Education, vol. 54, no. 4, pp. 877-888, 2010.

[11] Y. C. Hu and P. C. Liao, "Finding critical criteria of evaluating electronic service quality of Internet banking using fuzzy multiple-criteria decision making," Applied Soft Computing Journal, vol. 11, no. 4, pp. 3764-3770, 2011.

[12] X. Yu, S. Guo, J. Guo, and X. Huang, "Rank B2C e-commerce websites in e-alliance based on AHP and fuzzy TOPSIS," Expert Systems with Applications, vol. 38, no. 4, pp. 3550-3557, 2011.

[13] T. H. Hsu, L. C. Hung, and J. W. Tang, "A hybrid ANP evaluation model for electronic service quality," Applied Soft Computing, vol. 12, no. 1, pp. 72-81, 2012.

[14] M. Yurdakul, "Measuring long-term performance of a manufacturing firm using the Analytic Network Process (ANP) approach," International Journal of Production Research, vol. 41, no. 11, pp. 2501-2529, 2003. 
[15] V. Ravi, R. Shankar, and M. K. Tiwari, "Analyzing alternatives in reverse logistics for end-of-life computers: ANP and balanced scorecard approach," Computers and Industrial Engineering, vol. 48, no. 2, pp. 327-356, 2005.

[16] Z. Ma, C. Shao, S. Ma, and Z. Ye, "Constructing road safety performance indicators using fuzzy delphi method and grey delphi method," Expert Systems with Applications, vol. 38, no. 3, pp. 1509-1514, 2011.

[17] A. Hartman, "Reaching consensus using the Delphi technique," Educational Leadership, vol. 38, pp. 495-497, 1981.

[18] T. J. Murry, L. L. Pipino, and J. P. Gigch, "A pilot study of fuzzy set modification of Delphi," Human Systems Management, vol. 5, no. 1, pp. 76-80, 1985.

[19] A. Ishikawa, M. Amagasa, T. Shiga, G. Tomizawa, R. Tatsuta, and H. Mieno, "The max-min Delphi method and fuzzy Delphi method via fuzzy integration," Fuzzy Sets and Systems, vol. 55, no. 3, pp. 241-253, 1993.

[20] T. H. Hus and T. H. Yang, "Application of fuzzy analytic hierarchy process in the selection of advertising media," Journal of Management and Systems, vol. 7, no. 1, pp. 19-40, 2000.

[21] Y. F. Kuo and P. C. Chen, "Constructing performance appraisal indicators for mobility of the service industries using Fuzzy Delphi Method," Expert Systems with Applications, vol. 35, no. 4, pp. 1930-1939, 2008.

[22] S. K. Liao and K. L. Chang, "Select televised sportscasters for Olympic games by analytic network process," Management Decision, vol. 47, no. 1, pp. 14-23, 2009.

[23] S. K. Liao and K. L. Chang, "Selecting key capabilities of TVshopping companies applying analytic network process," Asia Pacific Journal of Marketing and Logistics, vol. 21, no. 1, pp. 161173, 2009.

[24] S. K. Liao and K. L. Chang, "Selecting public relations personnel of hospitals by analytic network process," Journal of Hospital Marketing and Public Relations, vol. 19, no. 1, pp. 52-63, 2009.

[25] R. H. Lin, "An integrated FANP-MOLP for supplier evaluation and order allocation," Applied Mathematical Modelling, vol. 33, no. 6, pp. 2730-2736, 2009.

[26] Y. Oh, E. H. Suh, J. Hong, and H. Hwang, "A feasibility test model for new telecom service development using MCDM method: a case study of video telephone service in Korea," Expert Systems with Applications, vol. 36, no. 3, pp. 6375-6388, 2009.

[27] W. H. Wu, C. T. Lin, and K. H. Peng, "Determination of a hospital management policy using conjoint analysis in the analytic network process," Quality and Quantity, vol. 43, no. 1, pp. 145154, 2009.

[28] W. Y. Wu, H. A. Shih, and H. C. Chan, "The analytic network process for partner selection criteria in strategic alliances," Expert Systems with Applications, vol. 36, no. 3, pp. 4646-4653, 2009.

[29] J. K. Chen and I. S. Chen, "Using a novel conjunctive MCDM approach based on DEMATEL, fuzzy ANP, and TOPSIS as an innovation support system for Taiwanese higher education," Expert Systems with Applications, vol. 37, no. 3, pp. 1981-1990, 2010.

[30] S. K. Liao and K. L. Chang, "Measuring the managerial performance of TV companies," Journal of Information and Optimization Sciences, vol. 31, no. 3, pp. 603-623, 2010.

[31] S. K. Liao, K. L. Chang, and T. W. Tseng, "Optimal selection of program suppliers for tv companies using an analytic network process (ANP) approach," Asia-Pacific Journal of Operational Research, vol. 27, no. 6, pp. 753-767, 2010.
[32] C. T. Lin and M. C. Tsai, "Location choice for direct foreign investment in new hospitals in China by using ANP and TOPSIS," Quality and Quantity, vol. 44, no. 2, pp. 375-390, 2010.

[33] W. H. Tsai and W. Hsu, "A novel hybrid model based on DEMATEL and ANP for selecting cost of quality model development," Total Quality Management and Business Excellence, vol. 21, no. 4, pp. 439-456, 2010.

[34] M. L. Tseng, "Implementation and performance evaluation using the fuzzy network balanced scorecard," Computers and Education, vol. 55, no. 1, pp. 188-201, 2010.

[35] İ. Yüksel and M. Dağdeviren, "Using the fuzzy analytic network process (ANP) for Balanced Scorecard (BSC): a case study for a manufacturing firm," Expert Systems with Applications, vol. 37, no. 2, pp. 1270-1278, 2010.

[36] S. K. Liao, Y. C. Chen, K. L. Chang, and T. W. Tseng, "Assessing the performance of Taiwanese tour guides," African Journal of Business Management, vol. 5, no. 4, pp. 1325-1333, 2011.

[37] S. Altuntas, T. Dereli, and M. K. Yilmaz, "Multi-criteria decision making methods based weighted SERVQUAL scales to measure perceived service quality in hospitals: a case study from Turkey," Total Quality Management and Business Excellence, vol. 23, pp. 1379-1395, 2012.

[38] Y. C. Hu, J. H. Wang, and R. Y. Wang, "Evaluating the performance of Taiwan homestay using analytic network process," Mathematical Problems in Engineering, vol. 2012, Article ID 827193, 24 pages, 2012.

[39] H. Y. Kang, A. H. I. Lee, C. C. Chang, and M. S. Kang, "A model for selecting technologies in new product development," Mathematical Problems in Engineering, vol. 2012, Article ID 358129, 17 pages, 2012.

[40] T. L. Saaty, Decision Making with Dependence and Feedback: The Analytic Network Process, RWS Publication, Pittsburgh, Pa, USA, 1996.

[41] T. L. Saaty, The Analytic Hierarchy Process: Planning, Priority Setting, Resource Allocation, McGraw-Hill International, New York, NY, USA, 1980. 


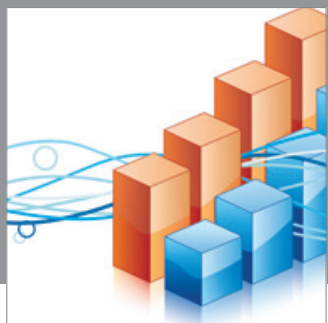

Advances in

Operations Research

mansans

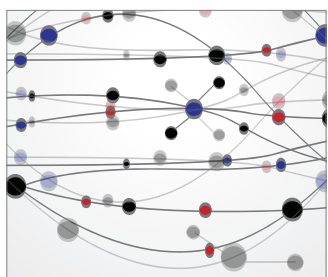

The Scientific World Journal
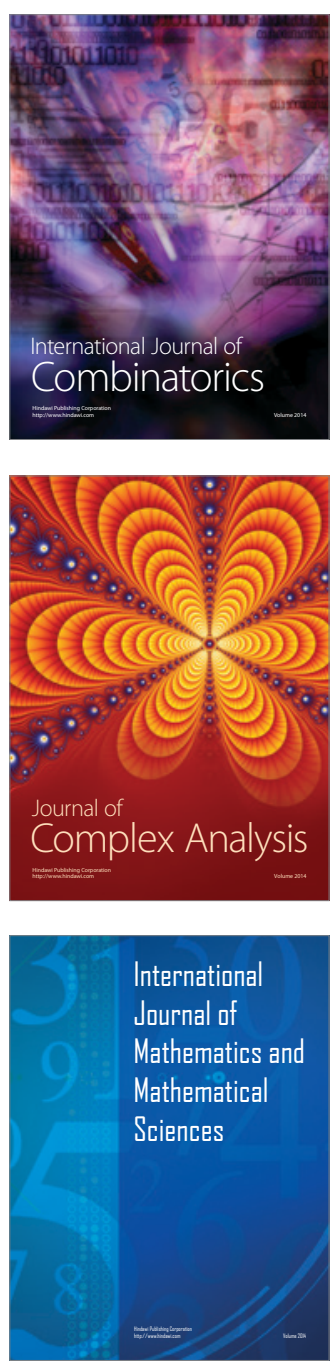
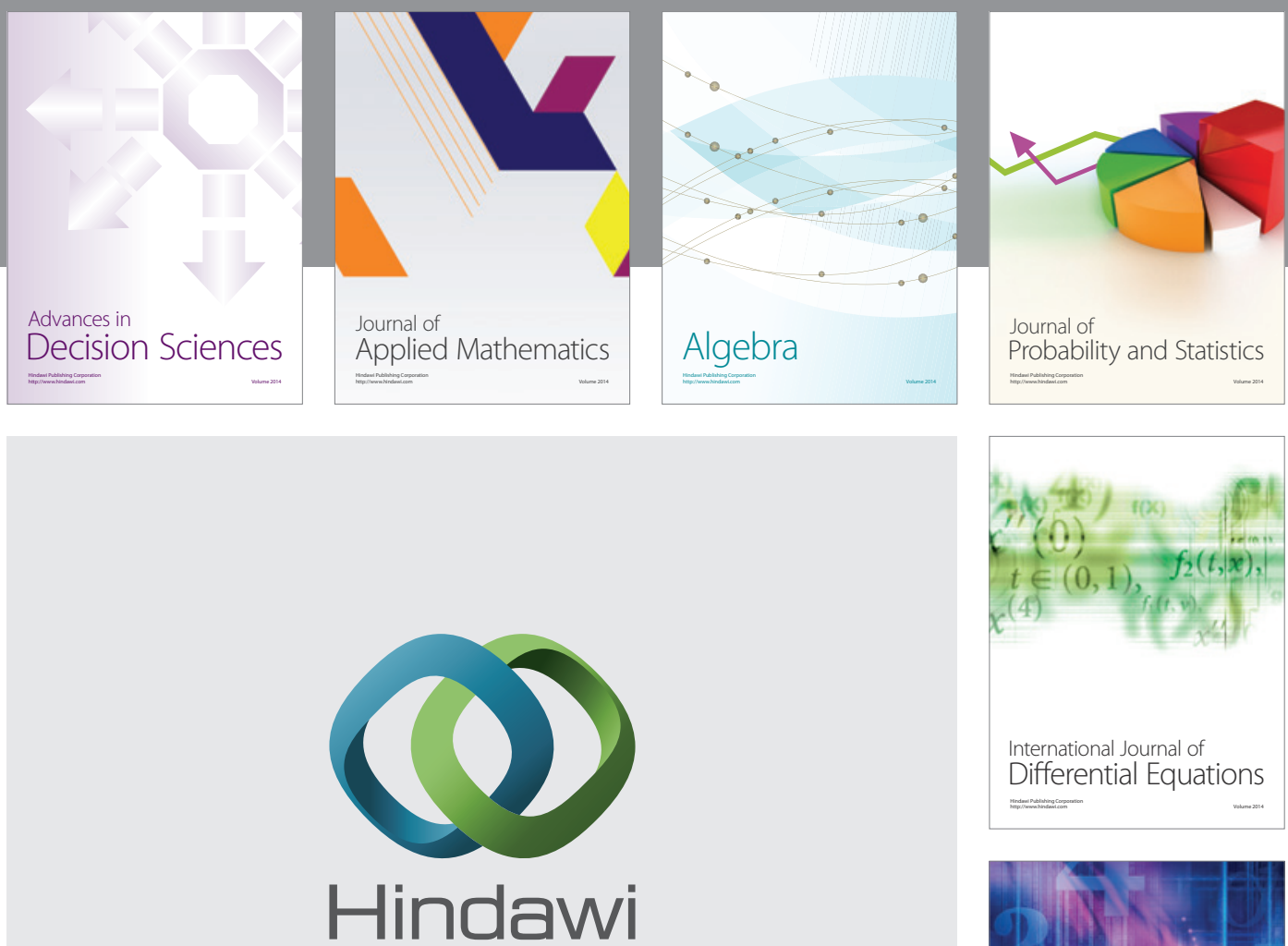

Submit your manuscripts at http://www.hindawi.com
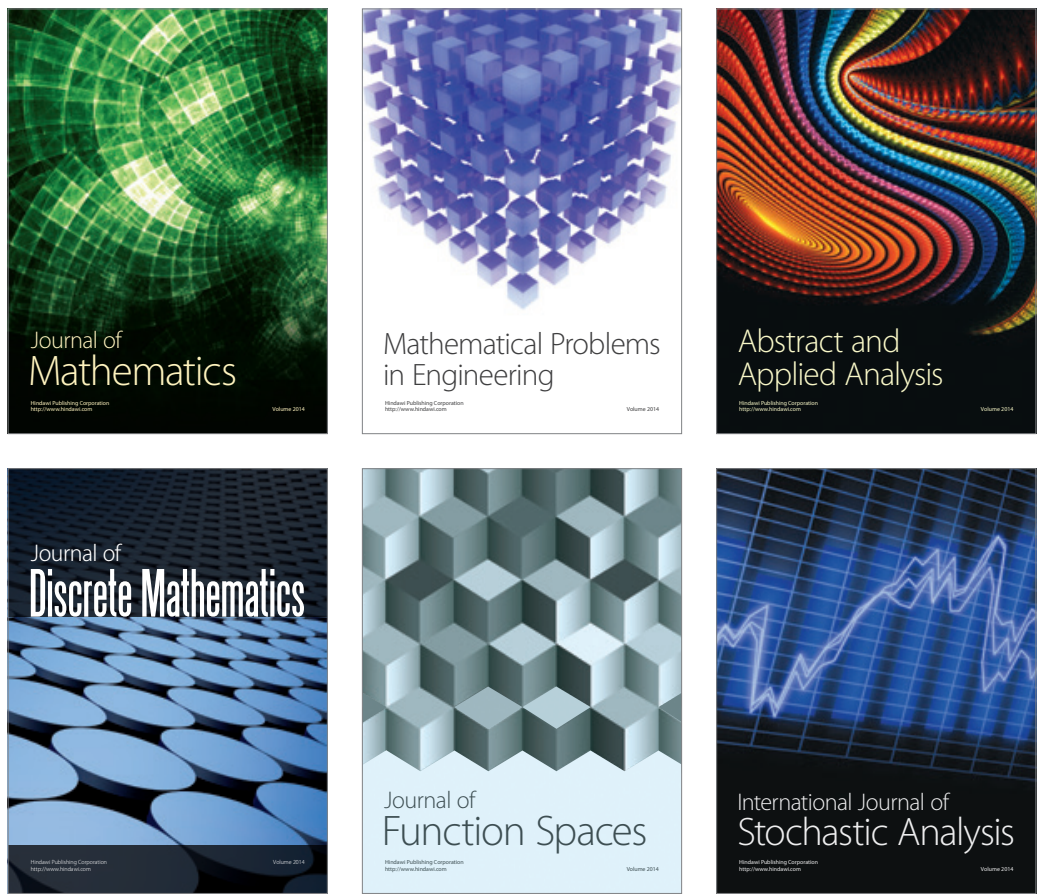

Journal of

Function Spaces

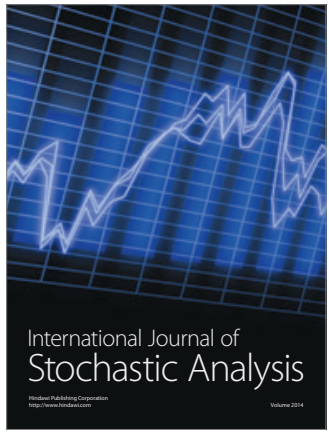

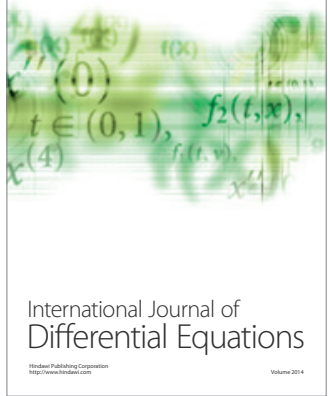
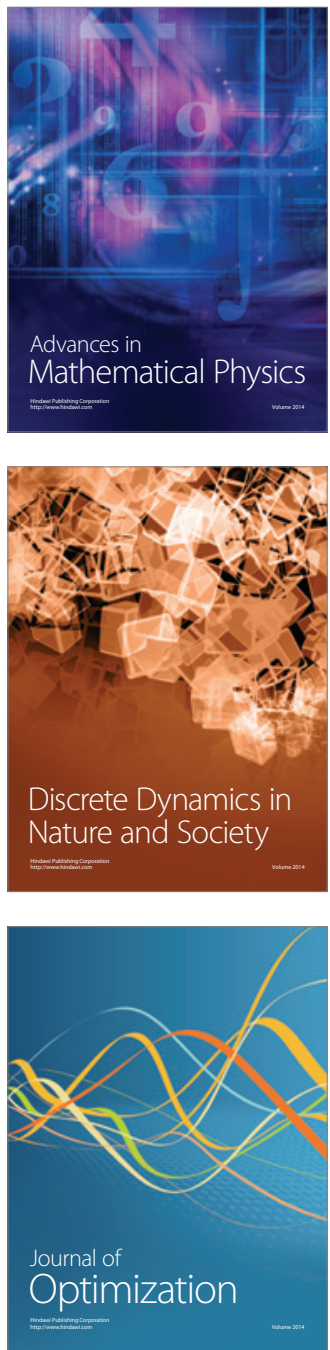